\title{
The Relationship between High Risk for Obstructive Sleep Apnea and General and Central Obesity: Findings from a Sample of Chilean College Students
}

\author{
Adaeze C. Wosu, ${ }^{1}$ Juan Carlos Vélez, ${ }^{2}$ Clarita Barbosa, ${ }^{2}$ Asterio Andrade, ${ }^{2}$ Megan Frye, ${ }^{2}$ \\ Xiaoli Chen, ${ }^{1}$ Bizu Gelaye, ${ }^{1}$ and Michelle A. Williams ${ }^{1}$ \\ ${ }^{1}$ Department of Epidemiology, Multidisciplinary International Research Training Program, Harvard School of Public Health, \\ 677 Huntington Avenue, Kresge 500, Boston, MA 02115, USA \\ ${ }^{2}$ Centro de Rehabilitación Club de Leones Cruz del Sur, Suiza 1441, Punta Arenas, 6211525 Magallanes, Chile
}

Correspondence should be addressed to Adaeze C. Wosu; awosu@hsph.harvard.edu

Received 21 January 2014; Accepted 17 March 2014; Published 14 April 2014

Academic Editors: M. M. Al-Nozha, B. Wizner, and C. H. Wu

Copyright (c) 2014 Adaeze C. Wosu et al. This is an open access article distributed under the Creative Commons Attribution License, which permits unrestricted use, distribution, and reproduction in any medium, provided the original work is properly cited.

\begin{abstract}
This cross-sectional study evaluates the prevalence and extent to which high risk for obstructive sleep apnea (OSA) is associated with general obesity and central obesity among college students in Punta Arenas, Chile. Risk for OSA was assessed using the Berlin Questionnaire and trained research nurses measured anthropometric indices. Overweight was defined as body mass index (BMI) of $25-29.9 \mathrm{~kg} / \mathrm{m}^{2}$ and general obesity was defined as BMI $\geq 30 \mathrm{~kg} / \mathrm{m}^{2}$. Central obesity was defined as waist circumference $\geq 90$ centimeters $(\mathrm{cm})$ for males and $\geq 80 \mathrm{~cm}$ for females. Multivariate logistic regression models were fit to obtain adjusted odds ratios (OR) and $95 \%$ confidence intervals (CI). Prevalence of high risk for OSA, general obesity, and central obesity were $7.8 \%, 12.8 \%$, and $42.7 \%$, respectively. Students at high risk for OSA had greater odds of general obesity (OR 9.96; 95\% CI: 4.42-22.45) and central obesity (OR 2.78; 95\% CI 1.43-5.40). Findings support a strong positive association of high risk for OSA with obesity.
\end{abstract}

\section{Background}

Chile, an upper middle-income country in South America, has seen increases in the prevalence of overweight and obesity, well-established risk factors for conditions such as cancer, cardiovascular disease, and diabetes [1, 2]. In 1987, the prevalence of excess weight among 6-year-olds in Chile was $13 \%$; by 2000 , it had reached $27 \%$ [3]. According to a 2012 report by the Organization for Economic Cooperation and Development (OECD), 25.1\% of Chilean adults are obese and, among Chilean children aged 5-17 years, $27.1 \%$ of girls and $28.6 \%$ of boys are overweight or obese [4]. Like excess weight, sleep disorders, particularly sleep apneas, have been associated with hypertension $[5,6]$, coronary artery disease [7], myocardial infarction [8,9], heart failure [10], and diabetes [9]. Although reports have been published on the prevalence of obesity and of sleep apnea in Chilean adults and young children $[4,11]$, few reports have focused attention on the prevalence of obesity and sleep apnea among young adults, particularly college students transitioning from adolescence into adulthood. Moreover, the college years are often characterized by insufficient sleep, increased consumption of energy drinks and caffeinated beverages, and irregular meal and sleep patterns, which can have important consequences for overall health and wellbeing [12-15]. To address the paucity of literature on the epidemiology of obstructive sleep apnea (OSA) and adiposity indices among college students in Chile, and to lay groundwork for developing health promotion and disease prevention strategies, we conducted a cross-sectional study of students at four Chilean colleges. 
We investigated OSA risk and the extent to which high risk for OSA was associated with overweight, general obesity, and central obesity in this population.

\section{Methods}

2.1. Study Population. The study was conducted between December 2010 and June 2011 at four colleges in the Magallanes region of Chile: Universidad Tecnologica de Chile, Universidad del Mar, Universidad de Magallanes, and Universidad Santo Tomas. Detailed descriptions of the study procedures have been given previously [16]. Of the 994 full-time undergraduates who participated in the study, we excluded students who were above 35 years old or missing information on age, sleep apnea (i.e., The Berlin Questionnaire), or adiposity measures $(n=78)$. The final sample consisted of 916 students aged 18 to 35 who had complete exposure and outcome information.

2.2. Recruitment. Flyers promoting the study were posted throughout departments at the participating colleges. Interested students were invited to meet in a large room or an auditorium where they were informed about the study purpose and procedures and invited to complete anonymous questionnaires requesting demographic, lifestyle, and sleeprelated information. Students who gave informed consent and completed the questionnaires were invited to participate in a brief physical examination during which trained research nurses took cardiometabolic and anthropometric measures including height, weight, blood pressure (BP), pulse rate, waist circumference (WC), and hip circumference (HC). All study procedures were approved by the institutional review boards of Centro de Rehabilitación Club de Leones Cruz del Sur, Punta Arenas, Chile, and the University of Washington, USA. The Harvard School of Public Health Office of Human Research Administration, USA, granted approval to use the anonymized dataset for analyses.

2.3. Obstructive Sleep Apnea (OSA) Risk. OSA risk was evaluated using the Berlin Questionnaire. Since it was first developed in 1996, the Berlin Questionnaire has been validated and used extensively in clinical and epidemiologic research globally including Latin America [17-23]. Numerous validation studies have reported moderate to high consistency between results of the Berlin Questionnaire and parameters of polysomnography, particularly respiratory disturbance index $(\mathrm{RDI})>5$ and apnea-hypopnea index $(\mathrm{AHI}) \geq 5$, especially within clinical populations [24].

The questionnaire is divided into three categories $[19,25]$. Category 1 evaluates snoring characteristics and how often the respondent ceases breathing during sleep. Category 2 assesses frequency of feelings of fatigue or tiredness after waking as well as sleepiness while driving. Category 3 ascertains information about obesity and hypertension [17, 19]. In the first two categories, a participant is given a positive score if he or she responds with "yes" or experiences frequent symptoms (more than 3 to 4 times per week) in two or more questions within that category. For category 3, a participant is given a positive score if he or she is obese $\left(\mathrm{BMI} \geq 30 \mathrm{~kg} / \mathrm{m}^{2}\right)$ or has a history of hypertension. Participants with positive scores in two or more categories are classified as having a high risk for OSA [17].

2.4. General Obesity. Body mass index (BMI) was calculated as weight in kilograms divided by height in square meters $\left(\mathrm{kg} / \mathrm{m}^{2}\right)$. Categories of BMI were defined according to the World Health Organization (WHO) criteria (underweight: $<18.5 \mathrm{~kg} / \mathrm{m}^{2}$; normal: $18.5-24.9 \mathrm{~kg} / \mathrm{m}^{2}$; overweight: $25.0-29.9 \mathrm{~kg} / \mathrm{m}^{2}$; and obese: $\geq 30.0 \mathrm{~kg} / \mathrm{m}^{2}$ ). General obesity was defined as BMI $\geq 30.0 \mathrm{~kg} / \mathrm{m}^{2}$ [26].

2.5. Central Obesity. Central obesity was evaluated using the International Diabetes Federation (IDF) criteria for South American men and women, that is, $W C \geq 90 \mathrm{~cm}$ (for men) and $\mathrm{WC} \geq 80 \mathrm{~cm}$ (for women) [27]. Waist-to-hip ratio (WHR) was calculated by dividing WC by HC. WHR was further categorized by quartile distribution and central obesity defined as WHR in the top quartile. Each anthropometric measurement was taken twice, and the average was used in data analyses.

2.6. Covariates. Sociodemographic information collected included age, sex, and year in college. Lifestyle and behavioral characteristics included moderate or vigorous physical activity (yes versus no), cigarette smoking status (never, former, or current), alcohol consumption within the past year (no versus yes), and use of more than one energy or stimulant drink per week (no versus yes). Energy or stimulant drinks were defined as beverages used to boost energy levels, increase alertness, and enhance cognition and mood [16]. Examples of these beverages include coffee, yerba mate, cola, Red Bull, and Dark Dog. Other variables included self-rated health (good versus poor) and systolic and diastolic BP.

2.7. Statistical Analysis. High risk for obstructive sleep apnea (OSA), defined as described above, was the exposure and the outcomes of interest were overweight, general obesity, central obesity, BMI, WC, HC, and WHR. First, we examined the frequency distributions of sociodemographic, lifestyle, and behavioral characteristics of the students. Characteristics of participants were summarized using counts and percentages for categorical variables and mean values $( \pm$ standard deviations) for continuous variables. Student's $t$-tests and chi-square tests were used to calculate bivariate differences for continuous and categorical variables, respectively. We examined the frequency distribution of OSA risk according to sociodemographic, lifestyle, and behavioral characteristics. Multivariate linear regression models were used to assess the associations of high OSA risk with BMI, WC, $\mathrm{HC}$, and WHR. Multivariate logistic regression models were used to determine odds ratios (OR) and 95\% confidence intervals (CI) of the association of high OSA risk with general obesity $\left(\mathrm{BMI} \geq 30 \mathrm{~kg} / \mathrm{m}^{2}\right)$, central obesity according to the IDF criteria, and WHR in the top quartile. Confounding variables were considered a priori on the basis of their hypothesized 


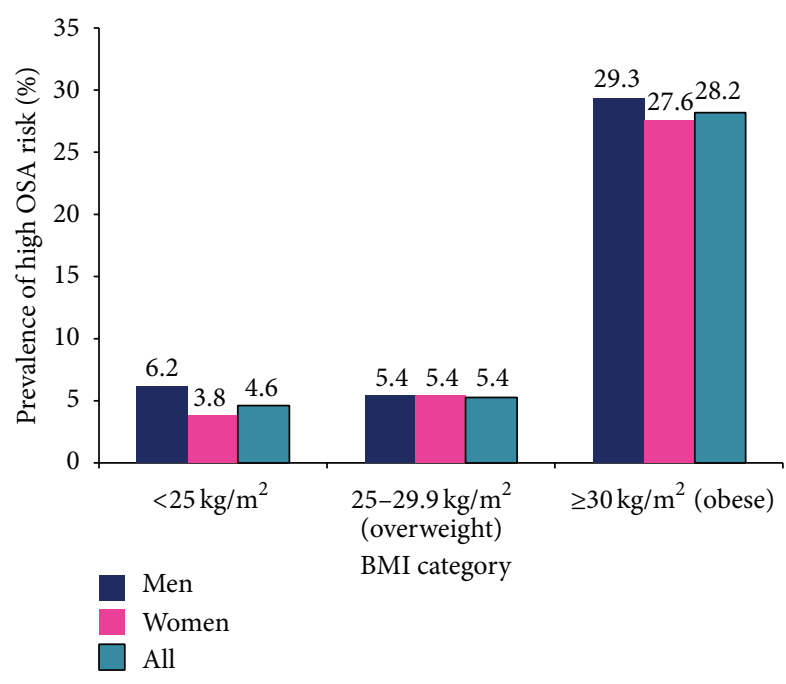

FIGURE 1: Prevalence of high OSA risk according to BMI category and gender.

relationship with OSA and adiposity. Potential confounders included age, sex, year in college, alcohol consumption, use of energy drinks, cigarette smoking status, self-rated health, BP, and participation in moderate or vigorous physical activity. We conducted stratified analyses to evaluate the extent to which, if at all, associations of high OSA risk with overweight, general obesity, and central obesity differed by sex, elevated BP, and subjects' self-rated health. All statistical analyses were performed using Statistical Analysis Software (SAS, version 9.3; SAS Institute, Cary, NC). All $P$ values are two-sided and set at $\alpha=0.05$.

\section{Results}

Of the 916 students included in the analysis, 69.5\% were females and the average reported age was $21.8( \pm 3.3)$ years. Approximately $7.8 \%$ were classified as having high risk for OSA as determined using previously published scoring and classification scheme of the Berlin Questionnaire. Approximately $28.3 \%$ of students were overweight (BMI: $25-29.9 \mathrm{~kg} / \mathrm{m}^{2}$ ) and $12.8 \%$ had general obesity according to WHO criteria (BMI $\geq 30 \mathrm{~kg} / \mathrm{m}^{2}$ ). Using the IDF definition, it was determined that $42.7 \%$ of students had central obesity (WC $\geq 90 \mathrm{~cm}$ for men or $\mathrm{WC} \geq 80 \mathrm{~cm}$ for women). High risk for OSA was associated with age, poor self-rated health, and cigarette smoking status. However, high risk for OSA was not associated with sex, year in college, systolic BP, diastolic BP, alcohol consumption, participation in moderate to vigorous physical activity, or consumption of more than one energy or stimulant drink per week (Table 1). Prevalence of high OSA risk was highest in the obese BMI category (Figure 1) and in individuals who were over 21 years old (Figure 2 ).

Table 2 shows the results of the fully adjusted models of the linear regression analyses. High OSA risk was statistically significantly associated with higher $\operatorname{BMI}(\beta: 3.25$; standard error: $0.63, P<0.001)$ and WHR $(\beta$ : 0.03 ; standard error: $0.01, P=0.02)$. High OSA risk was also associated with

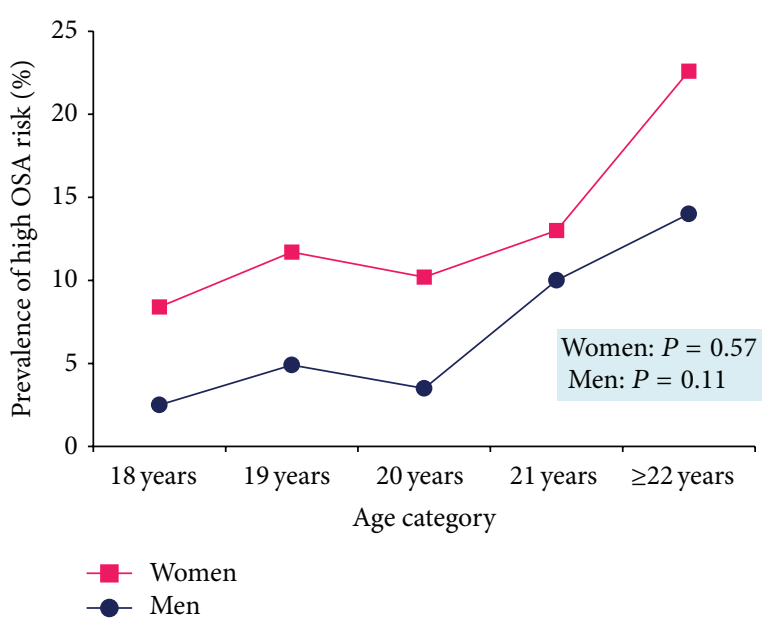

Figure 2: Prevalence of high OSA risk according to age group and gender.

higher WC $(\beta$ : 7.32; standard error: $1.54, P<0.001)$ and HC $(\beta$ : 5.00 ; standard error: $1.41, P<0.05)$.

Next, we completed logistic regression analyses. In the fully adjusted models, high risk for OSA was associated with almost 10-fold increased odds of general obesity (OR 9.96; 95\% CI 4.42-22.45) compared to low risk for OSA. Students with high OSA risk also had 2.78-fold odds of central obesity (OR 2.78; 95\% CI 1.43-5.40). However, the odds of high risk for OSA were not elevated by overweight status (OR 0.89; 95\% CI 0.35-2.23). Those with high risk for OSA were also more likely to be in the top quartile of WHR (i.e., WHR $\geq 0.8875$ ), although statistical significance was not achieved (OR 1.45; 95\% CI 0.71-2.95) (Table 3).

Similar strong positive associations between high risk for OSA and general obesity $\left(\mathrm{BMI} \geq 30 \mathrm{~kg} / \mathrm{m}^{2}\right.$ ) were evident within strata of sex (male or female), BP (nonelevated or elevated), and self-rated health (good or poor). High risk for OSA was not associated with overweight in strata of sex, BP, or self-rated health. For central obesity as defined by the IDF, the results of the stratified analyses were mixed. High risk for OSA was associated with central obesity only in men (OR 4.66; 95\% CI: 1.33-16.39), in individuals with elevated BP (OR 7.34; 95\% CI: 2.38-22.59), and in those with good selfrated health (OR 2.60; 95\% CI 1.28-5.28) while the findings in women and those with poor self-rated health were suggestive of a positive though not statistically significant association (Table 4).

\section{Discussion}

In this study of Chilean college students, $7.8 \%$ were classified as having high risk for OSA as defined by the Berlin Questionnaire and there was a high prevalence of overweight (28.3\%), general obesity (12.8\%), and central obesity $(42.7 \%)$. High OSA risk was strongly and positively associated with general obesity and central obesity, but not with overweight. 
TABLE 1: Characteristics of 916 college students in Chile, according to OSA risk.

\begin{tabular}{|c|c|c|c|c|}
\hline \multirow{2}{*}{ Characteristic } & \multirow{2}{*}{ Overall $(n=916)$} & \multicolumn{2}{|c|}{ OSA risk } & \multirow{2}{*}{$P$ value $^{\mathrm{c}}$} \\
\hline & & Low $(n=845)$ & $\operatorname{High}(n=71)$ & \\
\hline \multicolumn{5}{|l|}{ Demographic characteristics } \\
\hline Age, year, mean (SD) & $21.8(3.3)$ & $21.7(3.3)$ & $22.5(3.4)$ & 0.0425 \\
\hline Male, \% & 30.5 & 30.0 & 36.6 & 0.2429 \\
\hline \multicolumn{5}{|l|}{ Education (year in college), $\%$} \\
\hline First year & 37.3 & 37.4 & 35.7 & 0.4826 \\
\hline Second year & 30.7 & 30.5 & 34.3 & \\
\hline Third year & 18.5 & 19.0 & 12.9 & \\
\hline Fourth+ year & 13.4 & 13.1 & 17.4 & \\
\hline \multicolumn{5}{|l|}{ Lifestyle factors } \\
\hline Any physical activity participation, $\%$ & 53.9 & 55.5 & 52.1 & 0.5811 \\
\hline Alcohol consumption (past year), \% & 80.3 & 80.0 & 85.1 & 0.3105 \\
\hline \multicolumn{5}{|l|}{ Smoking status, \% } \\
\hline Nonsmoker & 42.7 & 44.2 & 24.6 & 0.0051 \\
\hline Current & 42.4 & 40.9 & 60.0 & \\
\hline Former & 14.9 & 14.9 & 15.4 & \\
\hline Use of $>1$ energy drinks per week, $\%$ & 54.3 & 53.8 & 60.6 & 0.2866 \\
\hline \multicolumn{5}{|l|}{ Self-rated health and blood pressure } \\
\hline Self-rated health ${ }^{\mathrm{a}}$ (poor), $\%$ & 12.1 & 11.4 & 22.2 & 0.0183 \\
\hline Systolic blood pressure (mmHg) & $121.5(14.4)$ & $121.3(14.3)$ & $124.6(15.6)$ & 0.0642 \\
\hline Diastolic blood pressure (mmHg) & $74.2(11.7)$ & $74.0(11.8)$ & $76.5(10.8)$ & 0.0932 \\
\hline \multicolumn{5}{|l|}{ Anthropometric measurements } \\
\hline BMI, kg/m², mean (SD) & $24.9(4.5)$ & $24.6(4.2)$ & $28.6(6.0)$ & $<0.0001$ \\
\hline \multicolumn{5}{|l|}{ WHO criteria of overweight and obesity $\left(\mathrm{kg} / \mathrm{m}^{2}\right), \%$} \\
\hline Underweight (BMI <18.5) & 1.5 & 1.7 & 0.0 & $<0.0001$ \\
\hline Normal weight (18.51-24.9) & 57.4 & 59.4 & 33.8 & \\
\hline Overweight (BMI: 25-29) & 28.3 & 29.0 & 19.7 & \\
\hline Obese (BMI $\geq 30)$ & 12.8 & 9.9 & 46.5 & \\
\hline Central obesity ${ }^{\mathrm{b}}, \%$ & 42.7 & 40.5 & 69.0 & $<0.0001$ \\
\hline Waist circumference, $\mathrm{cm}$, mean (SD) & $81.9(11.9)$ & $81.1(11.4)$ & $91.0(13.9)$ & $<0.0001$ \\
\hline Hip circumference, cm, mean (SD) & $97.9(10.0)$ & $97.3(9.7)$ & $104.6(11.0)$ & $<0.0001$ \\
\hline Waist-to-hip ratio, mean (SD) & $0.84(0.08)$ & $0.83(0.08)$ & $0.87(0.9)$ & 0.0007 \\
\hline Waist-to-hip ratio, top quartile (WHR $\geq 0.8875$ ), $\%$ & 24.9 & 23.8 & 36.6 & 0.0162 \\
\hline
\end{tabular}

SD: standard deviation; PA: physical activity; BP: blood pressure; BMI: body mass index.

a Self-rated health (SRH) was evaluated by asking, "how would you say your health compares to others your age." Poor SRH = worse than others my age. Good $\mathrm{SRH}=$ better or same as others my age.

${ }^{b}$ Based on the International Diabetes Federation (IDF) criteria for the definition of central obesity among South Americans: waist circumference $\geq 90 \mathrm{~cm}$ for men; waist circumference $\geq 80 \mathrm{~cm}$ for women.

${ }^{\mathrm{c}} \mathrm{Student} t$-test for continuous variables; chi-square for categorical variables.

4.1. Possible Biological Mechanisms Explaining the Relationship between OSA and Obesity. Although the exact pathway linking OSA and obesity remains somewhat unclear, it is recognized that obesity contributes to airway collapse during sleep by causing increased fat deposits around the upper airway, thus narrowing it and diminishing the activity of the muscles in that region [28-31]. Conversely, sleep apnea may contribute to excess weight and obesity through sleep loss and daytime sleepiness as apneic individuals rouse often to resume breathing and reenable unobstructed air flow [29]. Moreover, insufficient sleep has been associated with increased energy need and food intake [32]. On balance, available evidence suggests mechanisms that may underlay bidirectional relationships between increased adiposity and OSA.

4.2. Association between OSA and Obesity. We found strong positive associations of high OSA risk with general obesity, central obesity, BMI, and WHR. These findings are largely consistent with findings from numerous prior studies [3340]. In the Wisconsin Sleep Cohort Study, a 10\% weight gain was associated with approximately $32 \%$ increase in $\mathrm{AHI}$ as assessed by polysomnography [38]. In their study of patients at primary health care centers in Dubai, Mahboub et al. found 
TABLE 2: Linear regression analyses: associations of high OSA risk with anthropometric measurements among 916 college students in Chile.

\begin{tabular}{|c|c|c|c|c|c|c|c|c|}
\hline \multirow{2}{*}{ Model } & \multicolumn{2}{|c|}{ BMI $\left(\mathrm{kg} / \mathrm{m}^{2}\right)$} & \multicolumn{2}{|c|}{ Waist-to-hip ratio $(\mathrm{cm})$} & \multicolumn{2}{|c|}{ Waist circumference $(\mathrm{cm})$} & \multicolumn{2}{|c|}{ Hip circumference $(\mathrm{cm})$} \\
\hline & $\beta(\mathrm{SE})$ & $P$ value & $\beta(\mathrm{SE})$ & $P$ value & $\beta(\mathrm{SE})$ & $P$ value & $\beta(\mathrm{SE})$ & $P$ value \\
\hline Model 1: unadjusted & $3.93(0.54)$ & $<0.0001$ & $0.034(0.01)$ & 0.0007 & $9.84(1.43)$ & $<0.0001$ & $7.30(1.21)$ & $<0.0001$ \\
\hline $\begin{array}{l}\text { Model 2: adjusted for } \\
\text { demographic factors }\end{array}$ & $3.76(0.54)$ & $<0.0001$ & $0.027(0.01)$ & 0.0037 & $8.94(1.37)$ & $<0.0001$ & $7.03(1.21)$ & $<0.0001$ \\
\hline $\begin{array}{l}\text { Model 3: adjusted for } \\
\text { demographic \& } \\
\text { lifestyle factors }^{\mathrm{b}}\end{array}$ & $4.20(0.58)$ & $<0.0001$ & $0.028(0.01)$ & 0.0061 & $9.25(1.47)$ & $<0.0001$ & $7.37(1.30)$ & $<0.0001$ \\
\hline $\begin{array}{l}\text { Model 4: Model } 3+ \\
\text { blood pressure }^{c}\end{array}$ & $3.97(0.55)$ & $<0.0001$ & $0.026(0.01)$ & 0.0101 & $8.59(1.38)$ & $<0.0001$ & $6.83(1.24)$ & $<0.0001$ \\
\hline $\begin{array}{l}\text { Model 5: Model } 4+ \\
\text { self-rated health }^{\mathrm{d}}\end{array}$ & $3.25(0.63)$ & $<0.0001$ & $0.028(0.01)$ & 0.0193 & $7.32(1.54)$ & $<0.0001$ & $5.00(1.41)$ & 0.0004 \\
\hline
\end{tabular}

${ }^{\mathrm{a}}$ Demographic factors included age (continuous), sex, and education level.

${ }^{\mathrm{b}}$ Lifestyle factors included any physical activity participation, alcohol consumption (within the past year-yes/no), cigarette smoking (never, former, or current), and use of energy drinks (yes/no).

${ }^{c}$ Continuous blood pressure variables.

d Self-rated health (SRH) was evaluated by asking, "how would you say your health compares to others your age." Poor SRH = worse than others my age. Good $\mathrm{SRH}=$ better or same as others my age.

TABLE 3: Logistic regression analyses: associations of high OSA risk with overweight and obesity among 916 college students in Chile.

\begin{tabular}{|c|c|c|c|c|}
\hline \multirow{3}{*}{ Model } & WHO criteria & WHO criteria & & IDF criteria ${ }^{\mathrm{f}}$ \\
\hline & $\begin{array}{c}\text { BMI: } 25-29 \\
\text { versus } \mathrm{BMI}<25\end{array}$ & $\begin{array}{c}\mathrm{BMI} \geq 30 \text { versus } \mathrm{BMI} \\
<25\end{array}$ & $\begin{array}{l}\text { WHR } \geq 0.8875 \text { versus } \\
\text { WHR }<0.8875^{\mathrm{e}}\end{array}$ & $\begin{array}{c}\text { Central obesity versus } \\
\text { no central obesity }\end{array}$ \\
\hline & OR $(95 \% \mathrm{CI})$ & OR $(95 \% \mathrm{CI})$ & OR $(95 \% \mathrm{CI})$ & OR $(95 \% \mathrm{CI})$ \\
\hline Model 1: unadjusted & $1.23(0.63,2.42)$ & $8.45(4.76,15.00)$ & $1.85(1.11,3.08)$ & $3.27(1.94,5.51)$ \\
\hline $\begin{array}{l}\text { Model 2: adjusted for demographic } \\
\text { factors }^{\mathrm{a}}\end{array}$ & $1.09(0.55,2.17)$ & $8.26(4.59,14.86)$ & $1.65(0.96,2.86)$ & $3.26(1.92,5.56)$ \\
\hline $\begin{array}{l}\text { Model 3: adjusted for demographic } \\
\text { and lifestyle factors }{ }^{\text {b }}\end{array}$ & $1.53(0.74,3.17)$ & $10.24(5.30,19.81)$ & $1.68(0.93,3.05)$ & $3.37(1.90,5.97)$ \\
\hline Model 4: Model $3+$ blood pressure ${ }^{c}$ & $1.59(0.76,3.36)$ & $10.92(5.39,22.11)$ & $1.59(0.87,2.91)$ & $3.31(1.85,5.95)$ \\
\hline Model 5: Model $4+$ self-rated health ${ }^{\mathrm{d}}$ & $0.89(0.35,2.23)$ & $9.96(4.42,22.45)$ & $1.45(0.71,2.95)$ & $2.78(1.43,5.40)$ \\
\hline
\end{tabular}

BMI: body mass index; WHR: waist-to-hip ratio; IDF: International Diabetes Federation; WC: waist circumference; OR: odds ratio; 95\% CI: 95\% confidence interval.

${ }^{a}$ Demographic factors included age (continuous), sex, and education level.

${ }^{\mathrm{b}}$ Lifestyle factors included any physical activity participation, alcohol consumption (within the past year-yes/no), cigarette smoking (never, former, or current), and use of energy drinks (yes/no).

${ }^{\mathrm{c} C}$ Continuous blood pressure variables.

d Self-rated health (SRH) was evaluated by asking, "how would you say your health compares to others your age." Poor SRH = worse than others my age. Good $\mathrm{SRH}=$ better or same as others my age.

${ }^{\mathrm{e}} \mathrm{WHR} \geq 0.8875$ refers to the top quartile of WHR.

${ }^{\mathrm{f}}$ Central obesity as defined by the International Diabetes Federation (IDF): WC $\geq 90 \mathrm{~cm}$ for men and WC $\geq 80 \mathrm{~cm}$ for women in South America.

that approximately $70 \%$ of those at high risk for OSA had a $\mathrm{BMI} \geq 30 \mathrm{~kg} / \mathrm{m}^{2}$ while about $75 \%$ of the low risk group had BMI $<30 \mathrm{~kg} / \mathrm{m}^{2}$ [41]. Likewise, Blondet et al. found in a study of middle-aged Puerto Ricans that among men with BMI $<30 \mathrm{~kg} / \mathrm{m}^{2}, 98 \%$ had high risk for OSA compared to $50 \%$ among nonobese men. In addition, the authors noted that $70 \%$ of women with BMI $>28 \mathrm{~kg} / \mathrm{m}^{2}$ were at high risk for OSA compared to only $28 \%$ of those with BMI < $28 \mathrm{~kg} / \mathrm{m}^{2}$ [42]. The prevalence of high risk for OSA among students with general obesity in our study was substantially higher $(28.3 \%)$ compared to that in normal weight $(4.6 \%)$ and overweight $(5.4 \%)$ students. Although participants in many studies examining obesity and OSA risk are older and heavier than our population, significant positive associations between sleep apnea and obesity have also been found in pediatric and adolescent populations [43-46].

While we found no association between overweight BMI category and high risk for OSA in our sample, Peppard et al. observed a positive association between overweight BMI category and AHI in the Wisconsin Sleep Cohort Study [47]. Despite our finding of no association, overweight students should be targeted for interventions as these students are at higher risk for obesity in the near future compared to normal weight students. 
TABLE 4: Stratified analysis for the association of high OSA risk with overweight, general obesity, and central obesity, by sex, blood pressure, and self-rated health ${ }^{1}$.

\begin{tabular}{|c|c|c|c|c|}
\hline Stratified variable & $\begin{array}{l}\text { All participants } \\
\qquad N=916\end{array}$ & $\begin{array}{c}\text { WHO criteria } \\
\text { BMI: } 25-29 \text { versus }<25 \\
\text { OR }(95 \% \text { CI })^{\mathrm{a}}\end{array}$ & $\begin{array}{c}\text { WHO criteria } \\
\text { BMI } \geq 30 \text { versus }<25 \\
\text { OR }(95 \% \mathrm{CI})^{\mathrm{a}} \\
\end{array}$ & $\begin{array}{c}\text { IDF criteria }{ }^{\mathrm{b}} \\
\text { Central obesity versus no } \\
\text { central obesity }\end{array}$ \\
\hline \multicolumn{5}{|l|}{ Sex } \\
\hline Male & 280 & $0.56(0.13,2.47)$ & $7.23(1.34,38.94)$ & $4.66(1.33,16.39)$ \\
\hline Female & 636 & $1.16(0.34,3.95)$ & $14.96(5.40,2.30)$ & $2.08(0.90,4.81)$ \\
\hline \multicolumn{5}{|c|}{ Elevated blood pressure $^{c}$} \\
\hline No & 381 & $0.58(0.12,2.94)$ & $8.71(2.26,33.59)$ & $1.12(0.39,3.22)$ \\
\hline Yes & 534 & $1.21(0.36,4.09)$ & $12.42(4.23,36.48)$ & $7.34(2.38,22.59)$ \\
\hline \multicolumn{5}{|l|}{ Self-rated health ${ }^{\mathrm{d}}$} \\
\hline Good & 667 & $0.72(0.25,2.07)$ & $8.21(3.52,19.16)$ & $2.60(1.28,5.28)$ \\
\hline Poor & 92 & $3.01(0.16,57.86)$ & $144.82(2.4, \infty)$ & $15.76(0.93,267.69)$ \\
\hline
\end{tabular}

BMI: body mass index; IDF: International Diabetes Federation; OR: odds ratio; 95\% CI: 95\% confidence interval.

${ }^{a}$ Except for the stratified variables, the following variables were adjusted for age (continuous), sex, education, any physical activity participation, alcohol consumption, cigarette smoking, use of energy drinks, and self-rated health.

${ }^{\mathrm{b}}$ Central obesity was defined by the International Diabetes Federation (IDF) criteria for South Americans: WC $\geq 90 \mathrm{~cm}$ for men and WC $\geq 80 \mathrm{~cm}$ for women.

${ }^{c}$ Elevated $\mathrm{BP}$ defined as systolic $\mathrm{BP} \geq 120 \mathrm{mmHg}$ or diastolic $\mathrm{BP} \geq 80 \mathrm{mmHg}$.

${ }^{\mathrm{d}}$ Self-rated health (SRH) was evaluated by asking, "how would you say your health compares to others your age." Poor SRH = worse than others my age. Good $\mathrm{SRH}=$ better or same as others my age.

4.3. Prevalence of High Risk for OSA. The prevalence of high risk for OSA in our sample (7.8\%) is higher than what is reported among US young adults. For instance, authors of a study among 1,845 students enrolled in a southeastern US college reported a prevalence of $4 \%$ as assessed using the SLEEP-50 survey [48]. However, our finding is lower than high OSA risk estimates reported for US adults (26\%) who participated in the 2005 Sleep in America Poll [40]. We found no significant difference in frequency of OSA risk by sex (9.3\% for men and $7.1 \%$ for women; $P=0.25$ ) within our sample, although other investigators have shown that men have a higher risk for OSA compared to women-the main hypothesis being that men tend to have more fat deposits in the upper part of the body, that is, around the neck, trunk, and abdomen [49].

4.4. Prevalence of Obesity. The prevalence of general obesity in our study $(12.8 \%)$ was relatively low when compared to the prevalence reported for Chilean adults by the OECD (25.1\%) or that determined from a multistage cluster sampling of adults $\geq 40$ years old in Santiago, Chile $(31.7 \%)[4,11]$. However, the combined prevalence of overweight and obesity (i.e., BMI $\geq 25 \mathrm{~kg} / \mathrm{m}^{2}$ ) in our study was greater than that observed in a study of 3,461 Chilean students aged 17-24 years (41.1\% versus 19\%) [50]. When we examined the frequency of BMI $\geq 25 \mathrm{~kg} / \mathrm{m}^{2}$ by age within our sample, there was still a high prevalence of excess weight in the respective groups: 18 24 year-olds (39.5\%) and 25-35 year-olds (48.4\%); $P=0.04$. The overall prevalence of central obesity as defined using the IDF criteria was $42.7 \%$. These high frequencies of overweight and obesity in young adulthood are of concern as they may have implications for the development of cardiometabolic conditions in later life.
4.5. Strengths and Limitations. Our study has several strengths. First, numerous validation studies have reported moderate to high consistency between results of the Berlin Questionnaire and parameters of polysomnography, the gold-standard for diagnosing sleep disorders [24]. Second, we employed various statistical methods and assessed the relationship between high OSA risk and various indices of adiposity. Third, the likelihood for misclassification of obesity was reduced as trained research nurses used standard protocols to take anthropometric measurements, thus avoiding reliance on students' self-report.

There are some limitations that should be considered when interpreting the results of our study. Given our crosssectional study design, we are unable to determine if high risk for OSA preceded obesity. Longitudinal studies are needed to clarify the temporal relationship between OSA and obesity. Another limitation is that participants were not sampled randomly; rather, we relied on subjects' willingness to participate. As such, our findings could be subject to volunteer bias. Approximately $8 \%$ of students were excluded because of incomplete information on sleep apnea or anthropometric data. We found no significant difference between the prevalence of poor self-rated heath among individuals in our sample and those who were excluded (12.1\% versus $6.8 \% ; P=0.29)$ nor any significant difference in the distribution of cigarette smoking status $(P=0.28)$. However, excluded students tended to be older than those in our sample (mean \pm SD age: $23.4 \pm 5.0$ versus $21.8 \pm 3.3 ; P<$ 0.01 ). Given that OSA risk increases with age, it is possible that we missed individuals with high OSA risk among those who had incomplete sleep apnea or anthropometric information. Thus, the prevalence of high risk for OSA in our study could be an underestimate. Conversely, given the high prevalence of obesity within this sample, the use of 
odds ratios may give an exaggeration of the true estimate. We cannot exclude the possibility of residual confounding by unmeasured factors such as socioeconomic status, dietary intake (e.g., consumption of fruits, vegetables, or fast foods), or student's course load. Finally, due to the relatively small sample size, the $95 \%$ confidence intervals for the estimates from the logistic regression and stratified analyses are quite large and imprecise.

\section{Conclusion}

Our findings support significant positive associations of high OSA risk with general obesity and central obesity. Additional longitudinal evidence is needed to establish the temporal relationship of OSA and obesity. If our findings are confirmed, health care services for college students should include health promotion and disease prevention strategies about the importance of maintaining healthy weight. Strategies should also include health education modules that may be used to improve students' knowledge about sleep disorders, as prevention and control of cardiometabolic risk factors in young adulthood may have implications for preventing and mitigating chronic disease burden in later life.

\section{Conflict of Interests}

The authors declare that there is no conflict of interests regarding the publication of this paper.

\section{Acknowledgments}

This work was supported by an Award from the National Institutes of Health, National Institute on Minority Health and Health Disparities (T37-MD001449000) and Corporación de Rehabilitación Club de Leones Cruz del Sur, Punta Arenas, Chile. The authors would like to thank Universidad de Magallanes, Universidad del Mar, Instituto Profesional Santo Tomás, and INACAP Punta Arenas, for granting them permission to conduct the study on their campuses.

\section{References}

[1] L. Gitlin and P. Fuentes, "The Republic of Chile: an upper middle-income country at the crossroads of economic development and aging," The Gerontologist, vol. 52, no. 3, pp. 297-305, 2012.

[2] L. Aballay, A. Eynard, M. Diaz, A. Navarro, and S. Munoz, "Overweight and obesity: a review of their relationship to metabolic syndrome, cardiovascular disease, and cancer in South America," Nutrition Reviews, vol. 71, no. 3, pp. 168-179, 2013.

[3] T. Lobstein, "Prevalence and trends in childhood obesity," in Obesity Epidemiology: From Aetiology to Public Health, D. Crawford, R. Jeffery, K. Ball, and J. Brug, Eds., p. 10, Oxford University Press, New York, NY, USA, 2nd edition, 2010.

[4] F. Sassi, M. Devaux, and H. Fisher, Obesity Update 2012, Organization for Economic Cooperation and Development, 2012.
[5] V. Somers, D. White, R. Amin et al., "Sleep apnea and cardiovascular disease: an American Heart Association/American College of Cardiology Foundation scientific statement from the American Heart Association Council for High Blood Pressure Research Professional Education Committee, Council on Clinical Cardiology, Stroke Council, and Council on Cardiovascular Nursing. In collaboration with the National Heart, Lung, and Blood Institute National Center on Sleep Disorders Research (National Institutes of Health)," Circulation, vol. 118, no. 10, pp. 1080-1111, 2008.

[6] D. Silverberg, A. Oksenberg, and A. Iaina, "Sleep-related breathing disorders as a major cause of essential hypertension: fact or fiction?" Current Opinion in Nephrology and Hypertension, vol. 7, no. 4, pp. 353-357, 1998.

[7] Y. Peker, H. Kraiczi, J. Hedner, S. Löth, A. Johansson, and M. Bende, "An independent association between obstructive sleep apnoea and coronary artery disease," European Respiratory Journal, vol. 14, no. 1, pp. 179-184, 1999.

[8] J. Hung, E. Whitford, R. Parsons, and D. Hillman, "Association of sleep apnoea with myocardial infarction in men," The Lancet, vol. 336, no. 8710, pp. 261-264, 1990.

[9] C. Lee, S. Khoo, B. Tai et al., "Obstructive sleep apnea in patients admitted for acute myocardial infarction: prevalence, predictors, and effect on microvascular perfusion," Chest, vol. 135, no. 6, pp. 1488-1495, 2009.

[10] R. McEvoy, "Obstructive sleep apnea and heart failure: two unhappy bedfellows," American Journal of Respiratory and Critical Care Medicine, vol. 169, no. 3, pp. 329-331, 2004.

[11] L. Bouscoulet, J. Vázquez-García, A. Muiño et al., "Prevalence of sleep related symptoms in four Latin American cities," Journal of Clinical Sleep Medicine, vol. 4, no. 6, pp. 579-585, 2008.

[12] J. Kang and S. Chen, "Effects of an irregular bedtime schedule on sleep quality, daytime sleepiness, and fatigue among university students in Taiwan," BMC Public Health, vol. 9, article 248, 6 pages, 2009.

[13] A. Al-Rethaiaa, A. Fahmy, and N. Al-Shwaiyat, "Obesity and eating habits among college students in Saudi Arabia: a cross sectional study," Nutrition Journal, vol. 9, no. 1, article 39, 10 pages, 2010.

[14] G. Curcio, M. Ferrara, and L. de Gennaro, "Sleep loss, learning capacity and academic performance," Sleep Medicine Reviews, vol. 10, no. 5, pp. 323-337, 2006.

[15] V. Lohsoonthorn, H. Khidir, G. Casillas et al., "Sleep quality and sleep patterns in relation to consumption of energy drinks, caffeinated beverages, and other stimulants among Thai college students," Sleep and Breath, vol. 17, no. 3, pp. 1017-1028, 2013.

[16] J. Velez, A. Souza, S. Traslavina et al., "The epidemiology of sleep quality and consumption of stimulant beverages among Patagonian Chilean college students," Sleep Disorders, vol. 2013, Article ID 910104, 10 pages, 2013.

[17] N. Netzer, R. Stoohs, C. Netzer, K. Clark, and K. Strohl, "Using the Berlin Questionnaire to identify patients at risk for the sleep apnea syndrome," Annals of Internal Medicine, vol. 131, no. 7, pp. 485-491, 1999.

[18] F. Chung, B. Yegneswaran, P. Liao et al., "Validation of the Berlin questionnaire and American Society of Anesthesiologists checklist as screening tools for obstructive sleep apnea in surgical patients," Anesthesiology, vol. 108, no. 5, pp. 822-830, 2008.

[19] A. Vaz, M. Drummond, P. Mota, M. Severo, J. Almeida, and J. Winck, "Translation of Berlin Questionnaire to Portuguese 
language and its application in OSA identifi cation in a sleep disordered breathing clinic," Revista Portuguesa de Pneumologia, vol. 17, no. 2, pp. 59-65, 2011.

[20] A. Saleh, M. Ahmad, and N. Awadalla, "Development of Arabic version of Berlin questionnaire to identify obstructive sleep apnea at risk patients," Annals of Thoracic Medicine, vol. 6, no. 4, pp. 212-216, 2011.

[21] C. Guindalini, F. Colugnati, R. Pellegrino, R. Santos-Silva, L. Bittencourt, and S. Tufik, "Influence of genetic ancestry on the risk of obstructive sleep apnoea syndrome," European Respiratory Journal, vol. 36, no. 4, pp. 834-841, 2010.

[22] O. Adewole, A. Hakeem, A. Fola, E. Anteyi, Z. Ajuwon, and G. Erhabor, "Obstructive sleep apnea among adults in Nigeria," Journal of the National Medical Association, vol. 101, no. 7, pp. 720-725, 2009.

[23] C. Moreno, F. Carvalho, C. Lorenzi et al., "High risk for obstructive sleep apnea in truck drivers estimated by the Berlin questionnaire: prevalence and associated factors," Chronobiology International, vol. 21, no. 6, pp. 871-879, 2004.

[24] J. Geiger-Brown, V. Rogers, K. Han, A. Trinkoff, R. Bausell, and S. Scharf, "Occupational screening for sleep disorders in 12-h shift nurses using the Berlin Questionnaire," Sleep and Breathing, vol. 17, no. 1, pp. 381-388, 2013.

[25] F. Kapsimalis and M. Kryger, "Sleep breathing disorders in the U.S. female population," Journal of Women's Health, vol. 18, no. 8, pp. 1211-1219, 2009.

[26] B. Brumpton, A. Langhammer, P. Romundstad, Y. Chen, and X.M. Mai, "General and abdominal obesity and incident asthma in adults: the HUNT study," European Respiratory Journal, vol. 41, no. 2, pp. 323-329, 2013.

[27] K. Alberti, P. Zimmet, and J. Shaw, "The metabolic syndromea new worldwide definition," The Lancet, vol. 366, no. 9491, pp. 1059-1062, 2005.

[28] J. Dempsey, S. Veasey, B. Morgan, and C. O'Donnell, "Pathophysiology of sleep apnea," Physiological Reviews, vol. 90, no. 1, pp. 47-112, 2010.

[29] G. Pillar and N. Shehadeh, "Abdominal fat and sleep apnea: the chicken or the egg?" Diabetes Care, vol. 31, supplement 2, pp. S303-S309, 2008.

[30] M. Brennick, A. Pack, K. Ko et al., "Altered upper airway and soft tissue structures in the New Zealand obese mouse," American Journal of Respiratory and Critical Care Medicine, vol. 179, no. 2, pp. 158-169, 2009.

[31] G. Nino, M. Gutierrez, A. Ravindra, C. Nino, and C. RodriguezMartinez, "Abdominal adiposity correlates with adenotonsillectomy outcome in obese adolescents with severe obstructive sleep apnea," Pulmonary Medicine, vol. 2012, Article ID 351037, 8 pages, 2012

[32] R. Markwald, E. Melanson, M. Smith et al., "Impact of insufficient sleep on total daily energy expenditure, food intake, and weight gain," Proceedings of the National Academy of Sciences of the United States of America, vol. 110, no. 14, pp. 5695-5700, 2013.

[33] N. Punjabi, J. Sorkin, L. Katzel, A. Goldberg, A. Schwartz, and P. Smith, "Sleep-disordered breathing and insulin resistance in middle-aged and overweight men," American Journal of Respiratory and Critical Care Medicine, vol. 165, no. 5, pp. 677682, 2002.

[34] G. Mallory Jr., D. Fiser, and R. Jackson, "Sleep-associated breathing disorders in morbidly obese children and adolescents," The Journal of Pediatrics, vol. 115, no. 6, pp. 892-897, 1989.
[35] Z. Udwadia, A. Doshi, S. Lonkar, and C. Singh, "Prevalence of sleep-disordered Breathing and sleep apnea in middle-aged urban Indian men," American Journal of Respiratory and Critical Care Medicine, vol. 169, no. 2, pp. 168-173, 2004.

[36] O. Resta, M. Foschino-Barbaro, G. Legari et al., "Sleep-related breathing disorders, loud snoring and excessive daytime sleepiness in obese subjects," International Journal of Obesity, vol. 25, no. 5, pp. 669-675, 2001.

[37] A. Palla, M. Digiorgio, N. Carpenè et al., "Sleep apnea in morbidly obese patients: prevalence and clinical predictivity," Respiration, vol. 78, no. 2, pp. 134-140, 2009.

[38] P. Peppard, T. Young, M. Palta, J. Dempsey, and J. Skatrud, "Longitudinal study of moderate weight change and sleepdisordered breathing," The Journal of the American Medical Association, vol. 284, no. 23, pp. 3015-3021, 2000.

[39] N. Kim, S. Lee, C. Eun et al., "Short sleep duration combined with obstructive sleep apnea is associated with visceral obesity in Korean adults," Sleep, vol. 36, no. 5, pp. 723-729, 2013.

[40] D. Hiestand, P. Britz, M. Goldman, and B. Phillips, "Prevalence of symptoms and risk of sleep apnea in the US population: results from the national sleep foundation sleep in America 2005 poll," Chest, vol. 130, no. 3, pp. 780-786, 2006.

[41] B. Mahboub, S. Afzal, H. Alhariri, A. Alzaabi, M. Vats, and A. Soans, "Prevalence of symptoms and risk of sleep apnea in Dubai, UAE," International Journal of General Medicine, vol. 6, pp. 109-114, 2013.

[42] M. Blondet, P. Yapor, G. Latalladi-Ortega, E. Alicea, A. TorresPalacios, and W. Rodriguez-Cintron, "Prevalence and risk factors for sleep disordered breathing in a Puerto Rican middleaged population," Sleep and Breathing, vol. 13, no. 2, pp. 175-180, 2009.

[43] K. Kang, P. Lee, W. Weng, and W. Hsu, "Body weight status and obstructive sleep apnea in children," International Journal of Obesity, vol. 36, no. 7, pp. 920-924, 2012.

[44] C. Marcus, S. Curtis, C. Koerner, A. Joffe, J. Serwint, and G. Loughlin, "Evaluation of pulmonary function and polysomnography in obese children and adolescents," Pediatric Pulmonology, vol. 21, no. 3, pp. 176-183, 1996.

[45] S. Verhulst, N. Schrauwen, D. Haentjens et al., "Sleepdisordered breathing in overweight and obese children and adolescents: prevalence, characteristics and the role of fat distribution," Archives of Disease in Childhood, vol. 92, no. 3, pp. 205-208, 2007.

[46] Y. Wing, S. Hui, W. Pak et al., "A controlled study of sleep related disordered breathing in obese children," Archives of Disease in Childhood, vol. 88, no. 12, pp. 1043-1047, 2003.

[47] P. Peppard, T. Young, J. Barnet, M. Palta, E. Hagen, and K. Hla, "Increased prevalence of sleep-disordered breathing in adults," American Journal of Epidemiology, vol. 177, no. 9, pp. 1006-1014, 2013.

[48] J. Gaultney, "The prevalence of sleep disorders in college students: impact on academic performance," Journal of American College Health, vol. 59, no. 2, pp. 91-97, 2010.

[49] A. Schwartz, S. Patil, A. Laffan, V. Polotsky, H. Schneider, and P. Smith, "Obesity and obstructive sleep apnea: pathogenic mechanisms and therapeutic approaches," Proceedings of the American Thoracic Society, vol. 5, no. 2, pp. 185-192, 2008.

[50] J. Piqueras, W. Kuhne, P. Vera-Villarroel, A. van Straten, and P. Cuijpers, "Happiness and health behaviours in Chilean college students: a cross-sectional survey," BMC Public Health, vol. 11, article 443, 10 pages, 2011. 


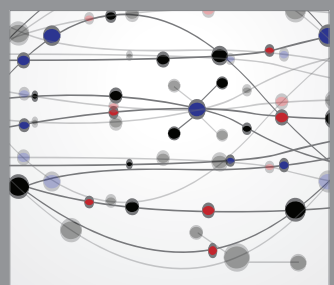

The Scientific World Journal
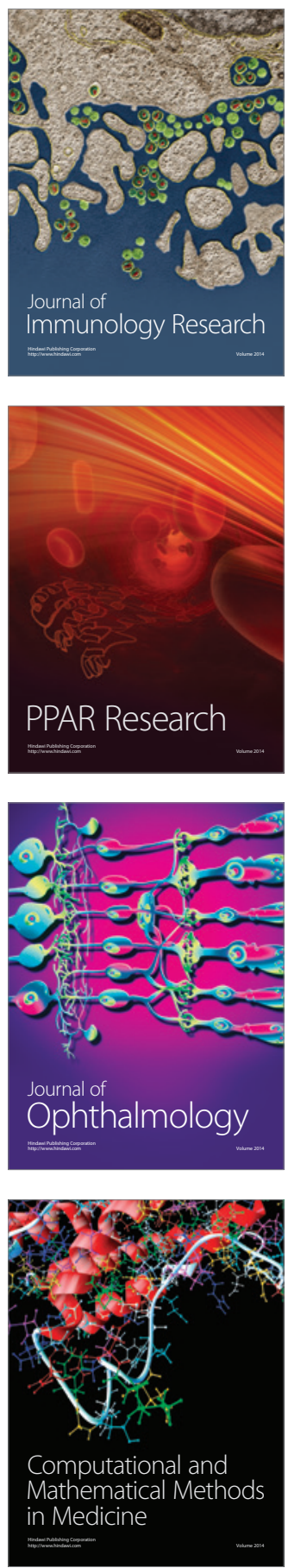

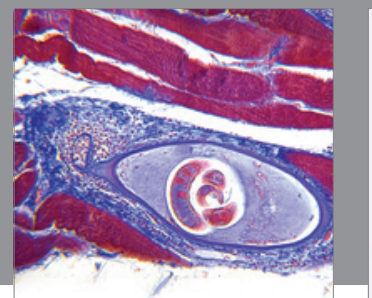

Gastroenterology

Research and Practice
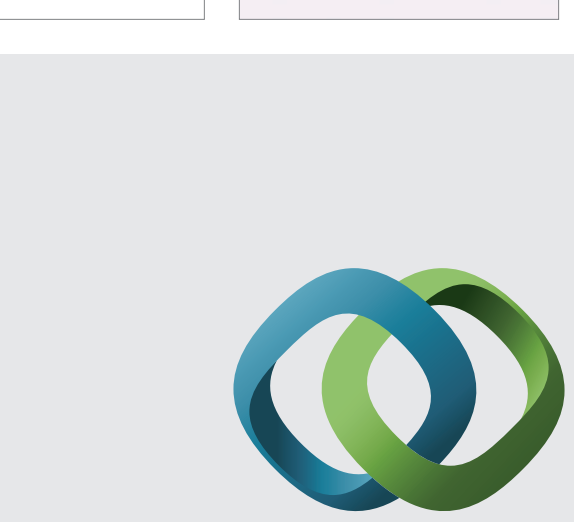

\section{Hindawi}

Submit your manuscripts at

http://www.hindawi.com
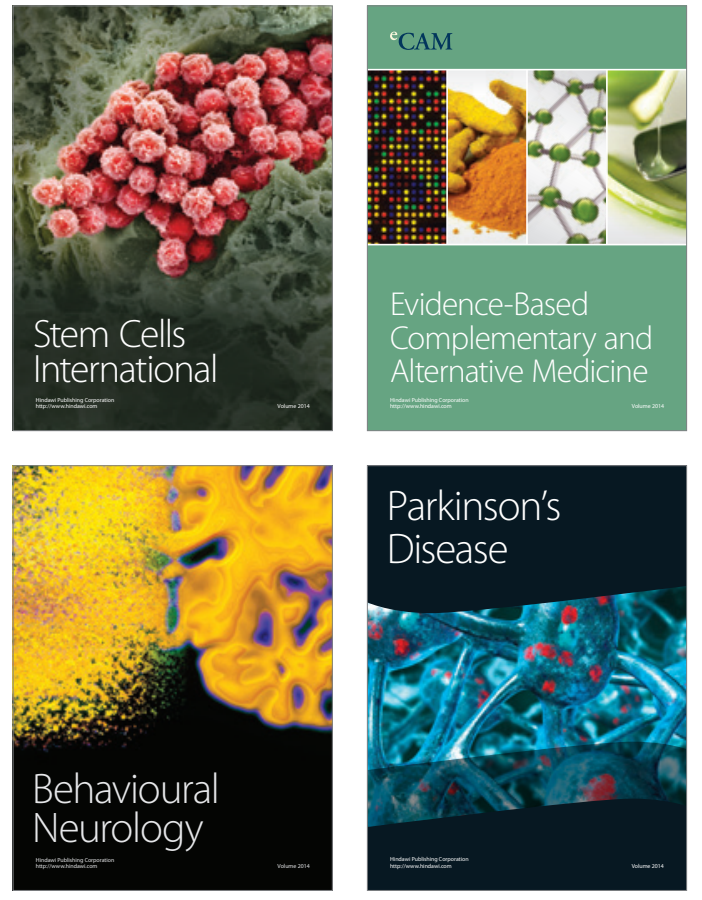
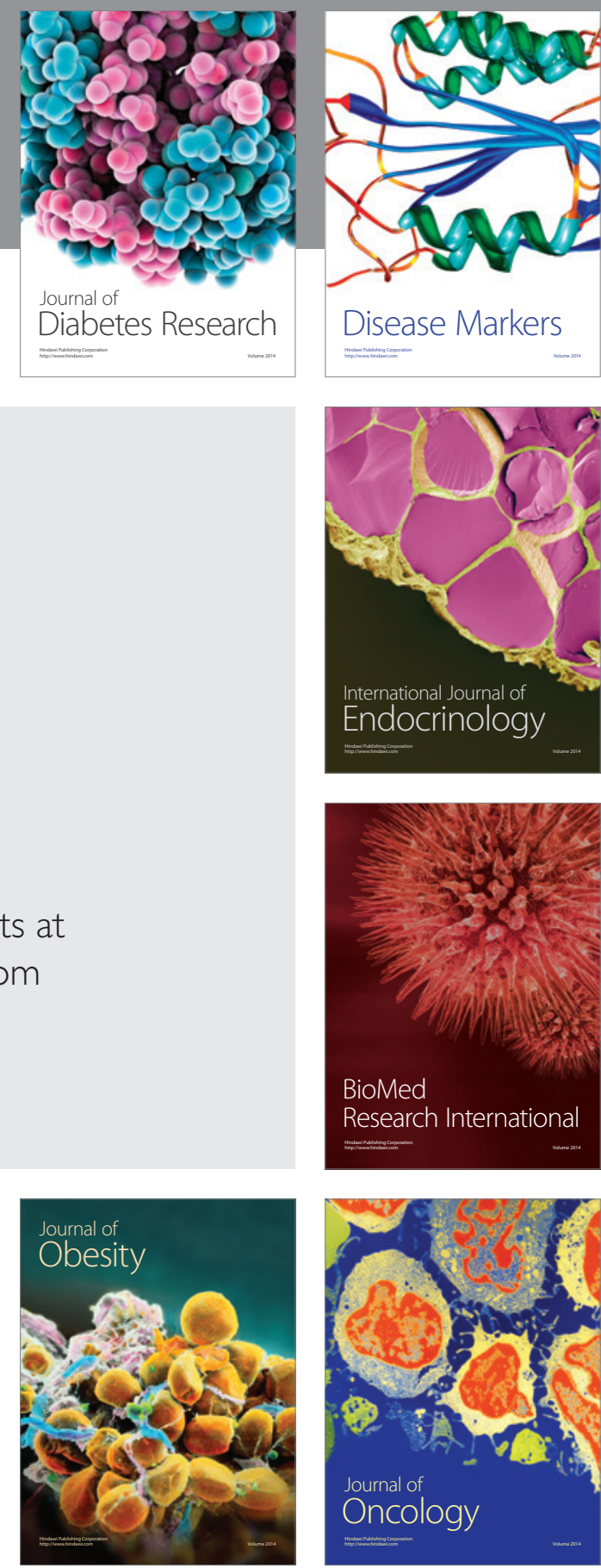

Disease Markers
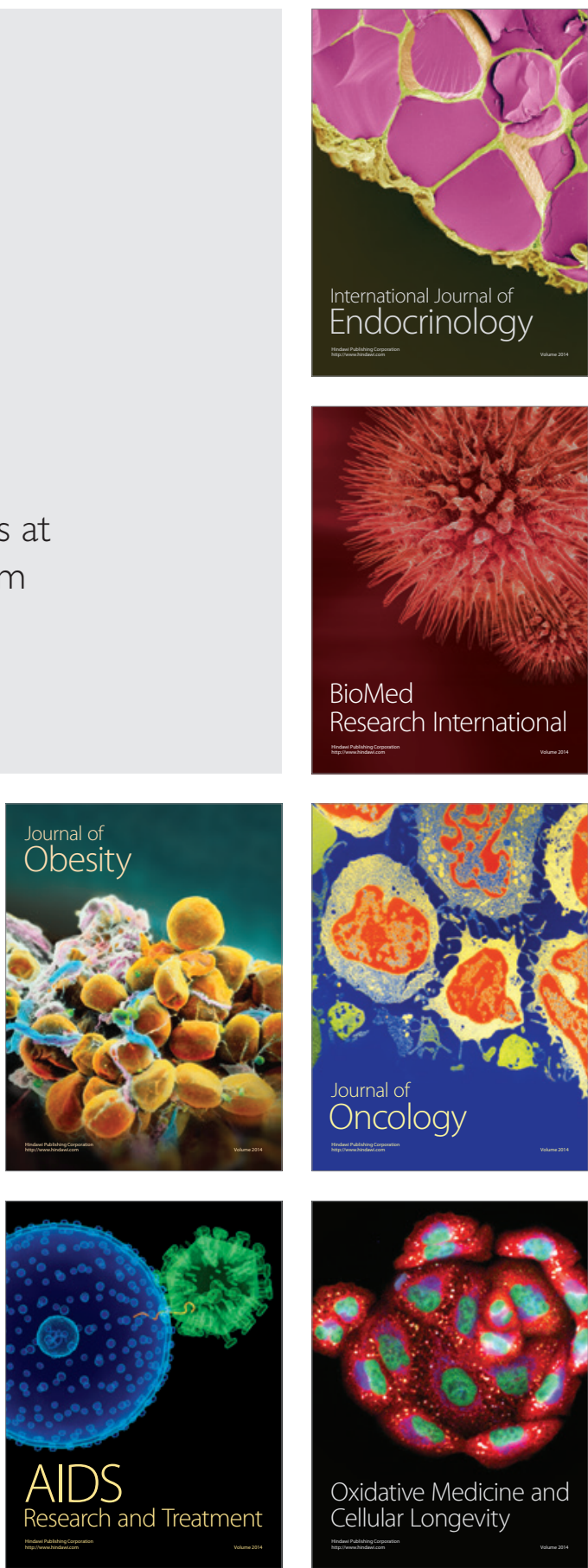